\title{
Pregnancy-Associated Plasma Protein A as an Independent Mortality Predictor in Long-Term Hemodialysis Patients
}

\author{
Marta Kalousováa Hana Benákováa Aleš Antonín Kuběna ${ }^{a}$ \\ Sylvie Dusilová-Sulkovác Vladimír Tesařb Tomáš Zimaa \\ anstitute of Clinical Biochemistry and Laboratory Diagnostics and ${ }^{b}$ Department of Nephrology, First Faculty of \\ Medicine, Charles University and General University Hospital, and ${ }^{\mathrm{C} D e p a r t m e n t}$ of Nephrology, Institute of \\ Clinical and Experimental Medicine, Prague, Czech Republic
}

\section{Key Words}

Cardiovascular mortality · Hemodialysis • Infection •

Mortality $\cdot$ Pregnancy-associated plasma protein A

\begin{abstract}
Background/Aims: Pregnancy-associated plasma protein A (PAPP-A) is a biomarker related to vascular damage. The aim of the study was to focus on PAPP-A and related parameters and their relationship to the prognosis of long-term hemodialysis (HD) patients. Methods: This is a prospective observational cohort study which included 261 long-term HD patients followed up for 5 years and 66 healthy subjects. PAPPA, placental growth factor (PIGF), matrix metalloproteinase 2 and 9 (MMP-2, MMP-9), insulin-like growth factor 1 (IGF-1), insulin-like growth factor binding protein-4 (IGFBP-4), and cardiac, nutritional and inflammatory parameters were measured at the beginning of the study and tested as predictors of mortality. Results: PAPP-A, PIGF, IGF-1, IGFBP-4 and MMP2 were significantly increased in HD patients compared to controls (PAPP-A $27.6 \pm 15.5 \mathrm{mlU} / \mathrm{l}$ in HD vs. $9.4 \pm 2.5 \mathrm{mlU} / \mathrm{l}$ in controls, $p<0.001)$. Increased PAPP-A was a significant independent predictor of overall mortality and mortality due to infection in the multivariate Cox analysis [HR $(95 \% \mathrm{Cl})$ :
\end{abstract}

1.237 (1.060-1.444), $p=0.007$, and $1.416(1.115-1.798), p=$ 0.004, per standard deviation, respectively]. PAPP-A was not related to cardiovascular mortality. Conclusion: Increased PAPP-A is a significant independent predictor of overall mortality and mortality due to infection but it was not related to cardiovascular mortality in this study.

Copyright $\odot 2011$ S. Karger AG, Basel

\section{Introduction}

Patients with chronic kidney disease have a significantly higher mortality rate compared with the general population, and cardiovascular complications are the major cause of death [1]. Pregnancy-associated plasma protein A (PAPP-A) is related to vascular damage and its serum levels represent a valuable biomarker of acute coronary syndromes [2].

PAPP-A is a high-molecular-weight protein, originally identified in plasma of pregnant women and used for screening of Down's syndrome in the first trimester of pregnancy [3]. In pregnancy the placenta is the main site of its synthesis [4], however its mRNA is present in several reproductive and non-reproductive tissues, e.g. kid-

\section{KARGER}

Fax +41613061234 E-Mail karger@karger.ch www.karger.com
(ㄷ) 2011 S. Karger AG, Basel

$1420-4096 / 12 / 0353-0192 \$ 38.00 / 0$

Accessible online at:

www.karger.com/kbr
Prof. Marta Kalousova, MD, $\mathrm{PhD}$

Institute of Clinical Biochemistry and Laboratory Diagnostics

First Faculty of Medicine, Charles University and General University Hospital

$\mathrm{Na}$ Bojišti 3, CZ-121 08 Prague 2 (Czech Republic)

Tel. +420 224964 212, E-Mail marta.kalousova@ seznam.cz 
ney, colon, endometrium and myometrium, and, although only in a very low concentration, it is also detectable in the serum of men and non-pregnant women [5]. PAPP-A belongs to a metzincin superfamily of metalloproteinases. It is responsible for proteolytic cleavage of insulin-like growth factor binding proteins (IGFBPs), mainly IGFBP- 4 but also 2 and 5, and so acts as a positive regulator of insulin-like growth factor-1 (IGF-1) bioavailability [6-8]. IGF-1 is involved in the pathogenesis of atherosclerosis $[9,10]$.

PAPP-A has also been demonstrated in eroded and ruptured atherosclerotic plaques and its serum levels were increased in patients with acute coronary syndromes [2]. Later it was shown that PAPP-A represents a valuable risk marker in patients with acute coronary syndromes [11] and its increase is of significance even in troponin-negative patients [12].

We have previously described the elevation of PAPP-A in long-term hemodialysis (HD) patients [13], the association of serum PAPP-A levels with renal function [14] and its decrease after successful kidney transplantation [15]. Additionally, our preliminary study performed in 40 long-term HD patients demonstrated higher PAPP-A levels in patients who died during the 20-month follow-up [16] and PAPP-A was shown to be an independent shorttime predictor of mortality in another group of $170 \mathrm{HD}$ patients [17]. Last but not least, the pretransplant serum concentration of PAPP-A also serves as a predictor of posttransplant cardiovascular events and chronic allograft nephropathy [18].

In this study we focused on PAPP-A and related parameters and the relationship of their serum levels to the prognosis of long-term HD patients in a 5-year followup. First, we were interested in placental growth factor (PIGF), another pregnancy protein and a member of the vascular endothelial growth factor family, which is also recognized as a marker of acute coronary syndromes [19]. Second, we studied matrix metalloproteinase (MMP)-2 and MMP-9, as PAPP-A is also a metalloproteinase. Third, we tested IGF-1 and IGFBP-4, molecules which are linked to PAPP-A action. Additionally, we looked at PAPP-A in the context of the established cardiac markers troponin I (cTnI) and brain natriuretic peptide (BNP), C-reactive protein (CRP) as an inflammatory marker and retinol as a newly identified mortality predictor of HD patients [20]. Apart from levels of generally accepted parameters, we hypothesized that mainly PAPP-A levels might also be of importance in long-term HD patients.

PAPP-A as Mortality Predictor in HD Patients

\section{Subjects and Methods}

\section{Study Design}

This study was designed as a prospective observational cohort study. It was performed in adherence to the principles of the Helsinki Declaration and approved by the Institutional Ethical Committee. All participants gave their informed consent prior to entering the study. The study was performed in six dialysis centers in the Czech Republic from November 2003 to December 2008 and involved 5 years of patient follow-up.

261 Caucasian patients on long-term HD, all of them with a stable clinical status, were enrolled. A consort flow diagram showing patients' flow was published previously [20]. Patients with an unstable clinical status, with acute cardiac problems or signs of acute infection, and patients with permanent catheters were not included. In these patients, data regarding basic characteristics and comorbidities were collected and biochemical parameters were measured at the beginning of the study.

All patients were followed up until death or for 5 years. During the follow-up, causes of death and eventual date of transplantation were recorded by contacting physicians from each dialysis center. Causes of death were finely classified by two independent physicians as cardiovascular (i.e. any cardiac or vascular death), infection, tumor or other.

66 unrelated healthy white subjects served as controls for comparison of biochemical parameters of interest.

\section{Patients}

The group of HD patients studied consisted of 141 men and 120 women, with a mean age of $63.5 \pm 13.1$ years. Their primary renal diagnosis was as follows: diabetic nephropathy in 51 cases, hypertensive nephropathy in 26 cases, interstitial nephritis in 70 cases, glomerulonephritis in 53 cases, polycystic kidney disease in 38 cases, and multifactorial in 23 cases. The majority of patients were dialyzed 3 times a week for $4 \mathrm{~h}$ and their dialysis treatment lasted for 2 years (min. 0, max. 27 years). 89\% of patients used a native arteriovenous fistula for dialysis; in the other cases an arteriovenous fistula with an artificial graft was used. $89 \%$ of patients were dialyzed with low-flux dialyzers and in the rest of the group either high-flux dialyzers or both high- and low-flux dialyzers were used. Dialyzer membranes were made of polysulfone (44.8\%), diacetate cellulose (34.5\%), triacetate cellulose, polymethylmethacrylate and polyamide. Table 1 depicts the laboratory characteristics of HD patients and their comparison with controls.

$33 \%$ of patients suffered from diabetes mellitus (half of them were treated with insulin) and $41 \%$ had dyslipidemia (27\% were treated with statins and $5 \%$ with fibrates). The case history of $84 \%$ of patients included hypertension, cardiovascular disease was present in $61 \%$ (acute myocardial infarction in 16.5\%), cerebrovascular diseases in $24 \%$ and peripheral vascular disease in $25 \% .11 \%$ of patients were evaluated as malnourished by the treating physicians, and $20 \%$ of patients were smokers. $71 \%$ of patients were currently treated with antihypertensive drugs (angiotensin-converting enzyme inhibitors or angiotensin II receptor-1 blockers in $51 \%$, $\beta$-blockers in $49 \%$, calcium channel blockers in $30 \%$, and nitrates in $18 \%$ of the total number of patients. Other drugs included diuretics (in 70\% of patients), aspirin or other antiplatelet drugs (67\% of patients), iron, erythropoietin (a weekly average dose of $75 \mathrm{IU} / \mathrm{kg}$ body weight), phosphate binders (predominant- 
ly calcium carbonate), and vitamin $\mathrm{D}$, and occasionally vitamin $\mathrm{B}$ and $\mathrm{C}$ supplementation.

In total, 146 patients died during the 5 years of follow-up. Causes of death were cardiovascular events in about half of the patients (71 patients), infection in 42 cases, tumor in 15 cases, and other causes in 18 cases. 52 patients were transplanted and 8 of them died ( 6 of them due to infection, 1 due to cardiovascular event, and 1 due to tumor). Concerning the non-transplanted patients, 138 died, of which 70 death were due to a cardiovascular event and 36 due to infection. Two patients were excluded from the study due to other reasons ( 1 due to improvement in renal function and discontinuation of dialysis, the other moved to another dialysis center and was finally lost to follow-up).

\section{Laboratory Analyses}

In HD patients, blood samples were collected after the long dialysis interval via puncture of the arteriovenous fistula before starting the dialysis session and prior to heparin administration. In the control subjects, blood was collected after overnight fasting via puncture of the cubital vein, simultaneously with blood collection for routine control examinations. Blood count and serum concentrations of routine biochemical parameters were determined in fresh samples. For special biochemical analysis, blood was collected into tubes without anticoagulant and with ethylenediaminetetraacetic acid for BNP determination, centrifuged for $10 \mathrm{~min}$ at 3,000 rpm and serum and plasma were frozen at $-80^{\circ} \mathrm{C}$.

PAPP-A was measured by TRACE (Time Resolved Amplified Cryptate Emission) technology using a Kryptor analyzer (Brahms $\mathrm{GmbH}$, Henningsdorf, Germany; www.brahms.de).

PIGF, IGFBP-4, MMP-2 and MMP-9 were measured using standard enzyme-linked immunosorbent assay kits (Quantikine; RD Systems, Minneapolis, Minn., USA; www.rndsystems.com).

IGF-1 was measured using a standard immunoradiometric assay (Immunotech, Marseille, France; www.immunotech.cz) on a Berthold LB2109 gamma counter (Berthold Technologies GmbH \& Co. KG, Germany; www.berthold.com).

BNP was assessed by the chemiluminescence method using a Centaur analyzer (Bayer, USA; www.bayer.com). cTnI was also measured by a chemiluminescence method, on a UniCel DxC 880i (Beckman Coulter Analyzer; www.immunotech.cz). Highly sensitive CRP was determined using turbidimetry on latex particles (Sevafarma a.s., Prague, Czech Republic; www.test-line.cz) and orosomucoid (acidic $\alpha_{1}$-glycoprotein) was measured nephelometrically. Retinol was determined by high-performance liquid chromatography apparatus (ECOM, Prague, Czech Republic; info@ecomsro.cz) using standard ClinRep kits (Recipe, Munich, Germany; www.recipe.de). Routine biochemical parameters and blood count were determined using standard laboratory methods with automated analyzers.

\section{Statistical Analyses}

Statistical analysis was performed using SPSS v.16 statistics software (SPSS Inc., Chicago, Ill., USA; www.spss.com).

The results of biochemical parameters are expressed as mean \pm SD. ANOVA (analysis of variance) with adjustment for age and gender was used for comparison of HD patients and controls and for comparison of subgroups of HD patients. Correlations between parameters were determined using Kendall's $\tau$ correlation coefficient due to non-normal distribution.
Patients' survival was evaluated using Kaplan-Meier analysis and uni- and multivariate Cox regression. Overall mortality, cardiovascular mortality and mortality due to infection were tested.

Hazard ratios (HR, relative risks of mortality) and appropriate 95\% confidence intervals (CI) were calculated using the Cox proportional hazard model. Transplantation was taken as a time-dependent covariate. Each potential predictor was tested in the univariate (unadjusted) Cox analysis. In a further analysis, stratification for membrane type (low- or high-flux) was used since no effect of center was observed. Multivariate Cox analysis was done using the backward method with standard exclusion criteria $\mathrm{p}>$ 0.1 . The two-step model was used - in the first step, only significant biochemical parameters from univariate analysis were tested to identify significant independent ones, and in the second step, significant biochemical predictors were tested together with demographic and clinical data to get final and fully adjusted results. All biochemical parameters, BMI and age were treated as continuous variables. HR and 95\% CI for biochemical parameters are given per $\mathrm{SD}$, for age per year.

Kaplan-Meier analysis was used to construct real survival curves. Transplantation was regarded as censored observations. Curves were compared using the log-rank test. Additionally, receiver operating characteristic (ROC) analysis for evaluation of PAPP-A on survival was performed. All results were considered statistically significant at $\mathrm{p}<0.05$.

\section{Results}

PAPP-A and Related Parameters at the Beginning of the Study

PAPP-A, PlGF, IGF-1, IGFBP-4 and MMP-2 were significantly increased, while MMP-9 did not differ in HD patients compared to controls (PAPP-A $27.6 \pm 15.5$ $\mathrm{mIU} / \mathrm{l}$ in $\mathrm{HD}$ vs. $9.4 \pm 2.5 \mathrm{mIU} / \mathrm{l}$ in controls, $\mathrm{p}<0.001$ ) (table 1; fig. 1).

PAPP-A in HD correlated significantly with other tested molecules: another pregnancy protein $\operatorname{PlGF}(\tau=$ $0.163, \mathrm{p}<0.001)$, MMP-2 $(\tau=0.133, \mathrm{p}=0.001)$ and MMP$9(\tau=-0.112, \mathrm{p}=0.007)$, molecules linked to its action IGF-1 $(\tau=-0.099, \mathrm{p}=0.02)$ and IGFBP-4 $(\tau=0.247, \mathrm{p}<$ $0.001)$ and cardiac markers $\mathrm{cTnI}(\tau=0.197, \mathrm{p}<0.001)$ and BNP $(\tau=0.198, p<0.001)$. Additionally, it was related to creatinine $(\tau=0.131, \mathrm{p}=0.002)$, but not to albumin, cholesterol, CRP, orosomucoid, and retinol.

\section{Results of Survival Analysis}

Table 2 provides the results of uni- and multivariate Cox analysis of all tested parameters. In the multivariate Cox analysis, PAPP-A, cTnI, albumin, creatinine, retinol, age, diabetes mellitus and any cardiac or vascular disease in the patient's history were identified as independent predictors for overall mortality. For cardiovascular mortality, cTnI, albumin, retinol, any cardiac or vascular dis- 
Table 1. Laboratory characteristics of HD patients compared with healthy controls

\begin{tabular}{|c|c|c|c|c|c|c|}
\hline Characteristic & HD patients & $\begin{array}{l}\text { HD patients } \\
\text { PAPP-A } \\
<30.8 \mathrm{mIU} / 1\end{array}$ & $\begin{array}{l}\text { HD patients } \\
\text { PAPP-A } \\
>30.8 \mathrm{mIU} / 1\end{array}$ & $\begin{array}{l}\text { Controls } \\
\text { PAPP-A }\end{array}$ & $\begin{array}{l}\mathrm{p} \text { value } \\
\text { HD vs. } \\
\text { controls }\end{array}$ & $\begin{array}{l}\mathrm{p} \text { value } \\
\text { HD patients with } \\
\text { PAPP-A <30.8 vs. } \\
>30.8 \mathrm{mIU} / 1\end{array}$ \\
\hline Patients, n (male/female) & $261(141 / 120)$ & $196(106 / 90)$ & $65(35 / 30)$ & $66(25 / 41)$ & 0.02 & 0.97 \\
\hline Age, years & $63.2 \pm 13.1$ & $62.8 \pm 13.6$ & $64.4 \pm 11.6$ & $58.7 \pm 9.2$ & 0.02 & 0.1 \\
\hline BMI & $25.4 \pm 4.5$ & $25.7 \pm 4.6$ & $24.5 \pm 4.2$ & $25.5 \pm 3.4$ & 0.9 & 0.07 \\
\hline Leukocytes, $\times 10^{9} / 1$ & $6.9 \pm 2.0$ & $7 \pm 1.9$ & $6.8 \pm 2$ & $6.4 \pm 1.7$ & 0.1 & 0.6 \\
\hline Hemoglobin, $\mathrm{g} / \mathrm{l}$ & $105.5 \pm 13.2$ & $105.3 \pm 13.6$ & $106.1 \pm 11.9$ & $141.0 \pm 10.1$ & $<0.001$ & 0.6 \\
\hline Hematocrit & $0.31 \pm 0.04$ & $0.31 \pm 0.04$ & $0.32 \pm 0.04$ & $0.41 \pm 0.03$ & $<0.001$ & 0.5 \\
\hline Thrombocytes, $\times 10^{9} / 1$ & $213 \pm 83$ & $214 \pm 84$ & $210 \pm 83$ & $254 \pm 49$ & $<0.001$ & 0.8 \\
\hline Creatinine, $\mu \mathrm{mol} / \mathrm{l}$ & $753 \pm 198$ & $750 \pm 203$ & $760 \pm 185$ & $88 \pm 13$ & $<0.001$ & 0.5 \\
\hline Urea, $\mathrm{mmol} / \mathrm{l}$ & $22.5 \pm 6.1$ & $23 \pm 6.1$ & $21.2 \pm 5.9$ & $4.9 \pm 1.1$ & $<0.001$ & 0.046 \\
\hline Uric acid, $\mu \mathrm{mol} / \mathrm{l}$ & $381.8 \pm 85.8$ & $381 \pm 90.5$ & $384.1 \pm 70.1$ & $278.1 \pm 64.5$ & $<0.001$ & 0.8 \\
\hline Albumin, $g / 1$ & $37.8 \pm 3.8$ & $37.8 \pm 3.7$ & $38 \pm 4.1$ & $44.4 \pm 2.6$ & $<0.001$ & 0.5 \\
\hline Transferrin, g/l & $1.8 \pm 0.4$ & $1.8 \pm 0.4$ & $1.8 \pm 0.4$ & $2.7 \pm 0.4$ & $<0.001$ & 0.3 \\
\hline Cholesterol, mmol/l & $4.7 \pm 1.1$ & $4.8 \pm 1.1$ & $4.6 \pm 1.1$ & $5.5 \pm 1.0$ & $<0.001$ & 0.3 \\
\hline LDL cholesterol, mmol/l & $2.5 \pm 0.8$ & $2.6 \pm 0.8$ & $2.5 \pm 0.9$ & $3.2 \pm 0.8$ & $<0.001$ & 0.036 \\
\hline HDL cholesterol, mmol/l & $1.3 \pm 0.4$ & $1.3 \pm 0.4$ & $1.3 \pm 0.3$ & $1.7 \pm 0.4$ & $<0.001$ & 0.4 \\
\hline Triacylglycerols, mmol/l & $2.0 \pm 1.2$ & $2.1 \pm 1.2$ & $1.9 \pm 1.2$ & $1.3 \pm 0.7$ & $<0.001$ & 0.2 \\
\hline Bilirubin, $\mu \mathrm{mol} / 1$ & $9.6 \pm 3.0$ & $9.2 \pm 2.7$ & $10.8 \pm 3.5$ & $11.4 \pm 5.6$ & $<0.001$ & $<0.001$ \\
\hline ALT, $\mu \mathrm{kat} / \mathrm{l}$ & $0.4 \pm 0.3$ & $0.3 \pm 0.3$ & $0.4 \pm 0.3$ & $0.4 \pm 0.2$ & 0.2 & 0.6 \\
\hline $\mathrm{CRP}, \mathrm{mg} / \mathrm{l}$ & $10.0 \pm 16.5$ & $9.6 \pm 17.0$ & $11 \pm 14.9$ & $3.3 \pm 2.4$ & 0.002 & 0.2 \\
\hline Fibrinogen, $g / 1$ & $4.2 \pm 1.2$ & $4.3 \pm 1.3$ & $4.2 \pm 1.2$ & $3.4 \pm 0.6$ & $<0.001$ & 0.96 \\
\hline Orosomucoid, g/l & $1.2 \pm 0.4$ & $1.1 \pm 0.4$ & $1.2 \pm 0.4$ & $0.8 \pm 0.2$ & $<0.001$ & 0.3 \\
\hline Retinol, mg/l & $1.7 \pm 0.6$ & $1.7 \pm 0.6$ & $1.6 \pm 0.7$ & $1.0 \pm 0.2$ & $<0.001$ & 0.5 \\
\hline Phosphate, $\mathrm{mmol} / \mathrm{l}$ & $1.9 \pm 0.6$ & $2 \pm 0.6$ & $1.9 \pm 0.5$ & $1.1 \pm 0.2$ & $<0.001$ & 0.2 \\
\hline Parathormone, pmol/l & $27.5 \pm 33.2$ & $27.5 \pm 33.5$ & $27.4 \pm 32.3$ & $3.1 \pm 1.5$ & $<0.001$ & 0.9 \\
\hline $\mathrm{PAPP}-\mathrm{A}, \mathrm{mIU} / \mathrm{l}$ & $27.6 \pm 15.5$ & $21 \pm 5.1$ & $47.3 \pm 19.2$ & $9.4 \pm 2.5$ & $<0.001$ & $<0.001$ \\
\hline $\mathrm{PlGF}, \mathrm{mg} / \mathrm{ml}$ & $13.0 \pm 9.1$ & $12.7 \pm 10.1$ & $14 \pm 5.1$ & $8.5 \pm 2.4$ & 0.001 & 0.3 \\
\hline MMP-2, ng/ml & $381 \pm 123$ & $375 \pm 122$ & $399 \pm 124$ & $244 \pm 70$ & $<0.001$ & 0.2 \\
\hline MMP-9, ng/ml & $467 \pm 348$ & $488 \pm 354$ & $406 \pm 327$ & $459 \pm 284$ & 0.8 & 0.1 \\
\hline IGF-1, $\mu \mathrm{g} / \mathrm{l}$ & $213 \pm 141$ & $216 \pm 136$ & $203 \pm 158$ & $146 \pm 66$ & $<0.001$ & 0.7 \\
\hline IGFBP-4, ng/ml & $1,380 \pm 505$ & $1,312 \pm 489$ & $1,585 \pm 502$ & $89 \pm 20$ & $<0.001$ & $<0.001$ \\
\hline cTnI, $\mu \mathrm{g} / \mathrm{l}$ & $0.03 \pm 0.03$ & $0.03 \pm 0.02$ & $0.05 \pm 0.04$ & $0.02 \pm 0.01$ & 0.002 & $<0.001$ \\
\hline $\mathrm{BNP}, \mathrm{pg} / \mathrm{ml}$ & $906 \pm 1,320$ & $751 \pm 971$ & $1,373 \pm 1,977$ & $17 \pm 16$ & $<0.001$ & 0.001 \\
\hline
\end{tabular}

Data are expressed as mean \pm SD. Statistics: ANOVA with adjustment for age and gender.

$\mathrm{ALT}=$ Alanine aminotransferase; $\mathrm{HDL}=$ high-density lipoprotein; $\mathrm{LDL}=$ low-density lipoprotein .

ease in the patient's history and transplantation, but not PAPP-A, remained independent predictors. For mortality due to infection, PAPP-A, creatinine and diabetes mellitus were significant. Significant independent mortality predictors and fully adjusted results of multivariate analysis are shown in table 3.

Kaplan-Meier analysis shows significantly worse survival of HD patients with PAPP-A levels in the upper quartile, i.e. $>30.8 \mathrm{mIU} / \mathrm{l}, \mathrm{p}=0.03$ (fig. 2). The main difference between the groups occurs within the first 200 days; however, even then the cumulative hazard risk is higher for patients with a higher PAPP-A. The significance of PAPP-A for patients' survival in the first 200 days is also demonstrated in ROC analysis - area under the curve (AUC) is $0.62, \mathrm{p}=0.038$ (fig. 3).

Taken together, high PAPP-A was demonstrated as an independent predictor of overall mortality and mortality due to infection in long-term HD patients. Surprisingly, its levels were not related to cardiovascular mortality. 
Table 2. Significant mortality predictors for overall, cardiovascular and infection-related mortality

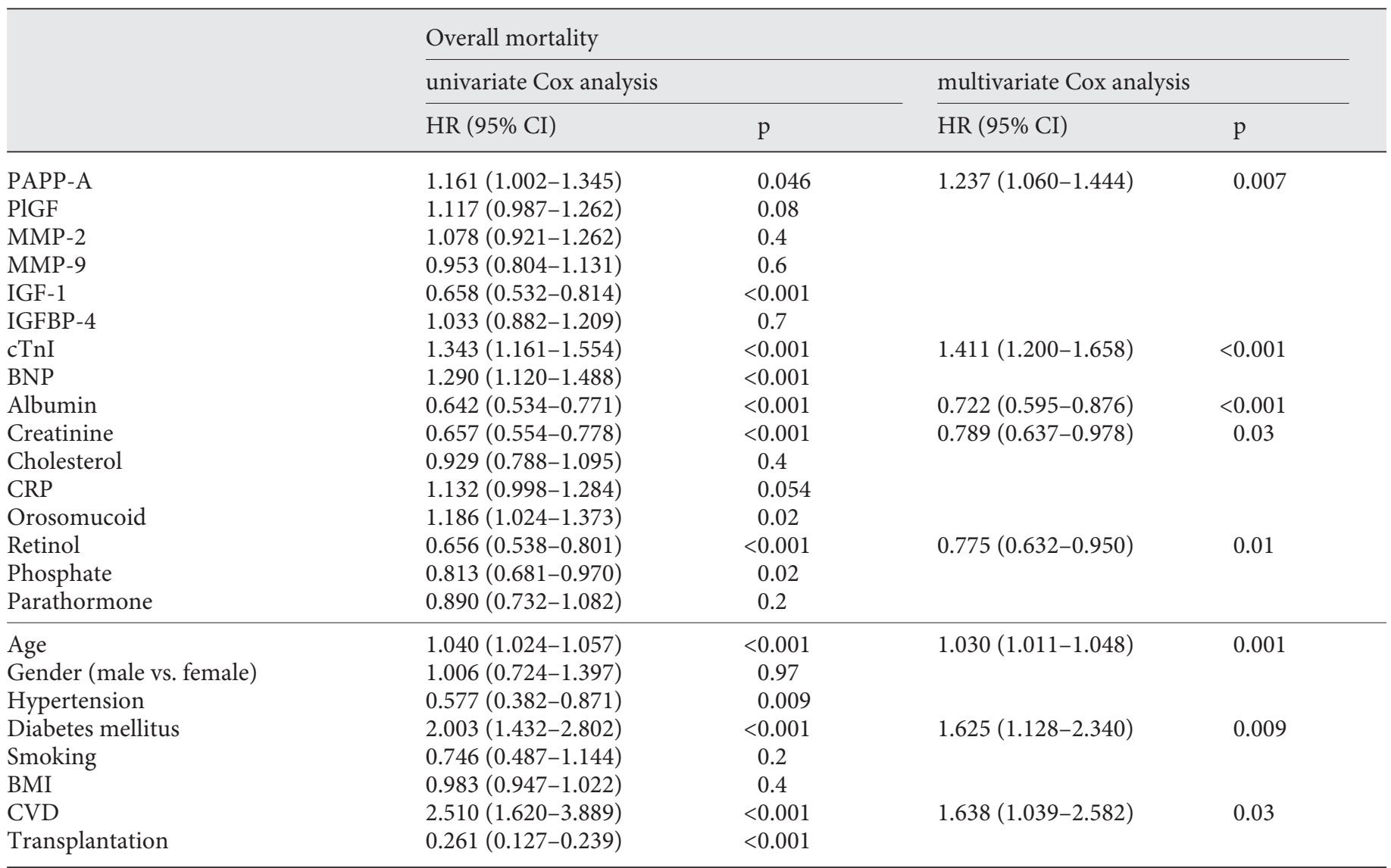

HRs and 95\% CIs for biochemical parameters are given per standard deviation and HRs for age are given per year. HRs were obtained using uni- or multivariate Cox analysis. Biochemical parameters, BMI and age were treated as continuous variables. Transplant was considered a time-dependent covariate in both univariate unadjusted and multivariate fully adjusted analysis. Fully adjusted analysis uses stratification for membrane type (low- or high-flux) and takes into consideration significant biochemical predictors in the first step and demographic and clinical data in the second step. CVD = Cardiovascular disease; n.s. = not significant (exclusion criteria of backward method $\mathrm{p}>0.1$ ).

\section{Discussion}

In this study we have identified PAPP-A as an independent predictor of overall mortality and mortality due to infection in long-term HD patients. Conversely, its serum levels were not linked to cardiovascular mortality in the studied group of HD patients. From the other tested markers, only IGF-1 was significant in univariate Cox analysis (overall mortality, cardiovascular mortality and mortality due to infection), however it lost its significance in multivariate analysis. Another pregnancy protein, PlGF, is inferior to PAPP-A.

PAPP-A has been identified as a prognostic marker or an independent predictor of cardiovascular events in patients with acute coronary syndromes $[11,12,21]$, in pa- tients with chronic stable angina pectoris [22] and in patients with peripheral atherosclerosis [23]. In type 1 diabetic patients with nephropathy, PAPP-A was associated with increased mortality in unadjusted analysis - however, after adjustment for traditional risk factors, the prognostic value of PAPP-A was no longer significant [24]. Concerning HD patients, to date only two studies evaluating the prognostic value of PAPP-A have been available, both of them with a lower number of patients and a markedly shorter follow-up period. The first one is our preliminary study performed in 40 long-term HD patients followed up for 20 months, which demonstrated higher PAPP-A levels at the beginning of the study in patients who died compared to survivors [16]. The second one is a study of $170 \mathrm{HD}$ patients followed up for 17 


\begin{tabular}{|c|c|c|c|c|c|c|c|}
\hline \multicolumn{4}{|c|}{ Cardiovascular mortality } & \multicolumn{4}{|c|}{ Mortality due to infection } \\
\hline HR (95\% CI) & $\mathrm{p}$ & HR (95\% CI) & $\mathrm{p}$ & HR $(95 \%$ CI $)$ & $\mathrm{p}$ & HR $(95 \%$ CI $)$ & $\mathrm{p}$ \\
\hline $1.072(0.843-1.365)$ & 0.6 & & & $1.257(0.986-1.601)$ & 0.06 & $1.416(1.115-1.798)$ & 0.004 \\
\hline $1.148(0.973-1.353)$ & 0.1 & & & $1.178(0.973-1.426)$ & 0.09 & & \\
\hline $1.096(0.880-1.363)$ & 0.4 & & & $1.139(0.849-1.527)$ & 0.4 & & \\
\hline $0.701(0.525-0.937)$ & 0.02 & & & $0.645(0.435-0.957)$ & 0.03 & & \\
\hline $1.094(0.879-1.362)$ & 0.4 & & & $0.937(0.691-1.269)$ & 0.7 & & \\
\hline $1.413(1.166-1.712)$ & $<0.001$ & $1.470(1.208-1.790)$ & $<0.001$ & $1.28(0.95-1.725)$ & 0.1 & & \\
\hline $1.353(1.123-1.629)$ & 0.001 & & & $1.296(0.989-1.699)$ & 0.06 & & \\
\hline $0.568(0.437-0.737)$ & $<0.001$ & $0.588(0.447-0.774)$ & $<0.001$ & $0.747(0.532-1.050)$ & 0.09 & & \\
\hline $0.721(0.569-0.914)$ & 0.007 & & & $0.580(0.423-0.795)$ & 0.007 & $0.672(0.487-0.926)$ & 0.02 \\
\hline $0.818(0.636-1.051)$ & 0.1 & & & $0.738(0.524-1.041)$ & 0.08 & & \\
\hline $0.968(0.773-1.212)$ & 0.8 & & & $0.577(0.341-0.978)$ & 0.04 & $0.621(0.364-1.058)$ & 0.08, n.s. \\
\hline $1.037(1.014-1.060)$ & 0.002 & & & $1.028(1.0003-1.056)$ & 0.047 & & \\
\hline $0.862(0.543-1.369)$ & 0.5 & & & $1.232(0.665-2.281)$ & 0.5 & & \\
\hline $0.499(0.284-0.875)$ & 0.02 & & & $0.597(0.276-1.294)$ & 0.2 & & \\
\hline $1.627(1.009-2.623)$ & 0.046 & & & $3.164(1.704-5.874)$ & $<0.001$ & $2.966(1.474-5.966)$ & 0.002 \\
\hline $0.590(0.309-1.123)$ & 0.1 & & & $0.685(0.303-1.549)$ & 0.4 & & \\
\hline $0.963(0.911-1.017)$ & 0.2 & & & $1.052(0.988-1.121)$ & 0.1 & & \\
\hline $4.658(2.123-10.220)$ & 0.001 & $3.753(1.699-8.289)$ & 0.001 & $1.724(0.855-3.476)$ & 0.1 & & \\
\hline $0.059(0.008-0.427)$ & 0.005 & $0.121(0.016-0.893)$ & 0.04 & $0.801(0.325-1973)$ & 0.6 & & \\
\hline
\end{tabular}

months which was performed at seven dialysis units in Switzerland [17]. PAPP-A was shown as an independent short-time predictor of mortality. The small number of deaths during the follow-up period (23 deaths) did not allow further subgroup analysis with stratification by etiology. Additionally, several studies were dedicated to PAPP-A in renal transplant recipients - its pretransplant serum concentration also serves as a predictor of posttransplant cardiovascular events and chronic allograft nephropathy [18] and could be a risk factor of delayed graft function [25].

PAPP-A is linked to inflammation and this relationship is bidirectional. PAPP-A expression is stimulated by tumor necrosis factor- $\alpha$ and interleukin-1 $\beta$ [26-28] and this cytokine-induced expression can be inhibited by the antioxidants $\mathrm{N}$-acetylcysteine [27] or polyphenol resveratrol [28]. PAPP-A action then increases IGF-1 bioavailability via proteolytic degradation of its binding proteins. IGF-1 possesses proatherogenic properties - it induces the migration of smooth muscle cells, macrophage activation, chemotaxis, LDL cholesterol uptake by macrophages, and cytokine release $[9,10]$. The relationship to inflammatory markers was also observed in serum in some studies - a significant correlation was found between PAPP-A and CRP in patients with acute coronary syndrome [2] and in our other study performed in patients with chronic kidney disease [14], and with CRP, interleukin- 6 and tumor necrosis factor- $\alpha$ in renal transplant recipients before transplantation [18]. Moreover, we have shown an association of PAPP-A serum levels with 


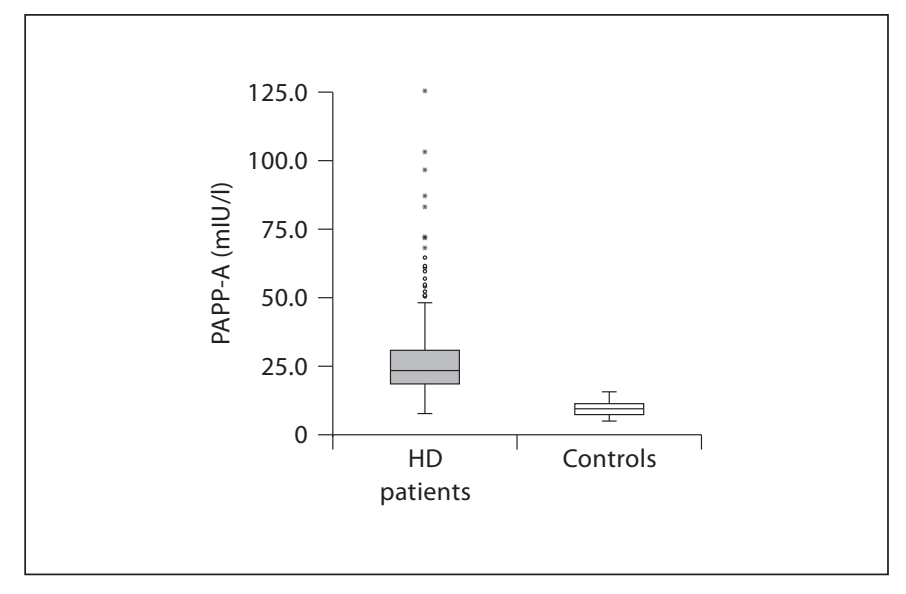

Fig. 1. PAPP-A in HD patients and healthy controls $(27.6 \pm 15.5$ vs. $9.4 \pm 2.5 \mathrm{mIU} / \mathrm{l} ; \mathrm{p}<0.001)$.

intragraft interstitial inflammation in a 3-month protocol biopsy [15]. Indeed, our results demonstrate PAPP-A as an independent predictor of mortality of HD patients due to infection. PAPP-A might therefore provide additional information for CRP, the first line marker of inflammation and the best known and most often determined acute phase reactant which was not significant in multivariate analysis. The relationship of PAPP-A to infection/inflammation was much more pronounced than that to cardiovascular disease.

It has also been suggested that PAPP-A may not have a causal effect in the determination of coronary syndromes, but can rather represent a sensitive signal of damage, similar to those exerted by other acute-phase proteins, being part of an endogenous compensatory pathway aimed at tissue physiological repair and replicative programs [29]. IGF-1 might rather provide protection against ischemic vascular disease due to its immunomodulatory and anti-inflammatory actions [30]. The decrease in the IGF-1 axis and the ratio of IGF-1 to IGFBP-3 was associated with increased rates of all-cause mortality and cardiac death in patients with heart failure [31], while another study did not show any effect of IGF-1 levels on the prognosis of chronic heart failure patients [32]. Surprisingly, in our study, PAPP-A correlated slightly but significantly and negatively with IGF-1. In line with this finding, increased IGF-1 levels were beneficial for patients' survival in unadjusted analysis but lost significance after adjustment for other risk factors. It is possible that IGF-1 bioavailability is also regulated by other factors and not only by PAPP-A, as PAPP-A did not cleave
IGFBP-3 in myoblasts in an in vitro experiment [33]. Measurement of PAPP-A and IGF-1 might not give the same information due to complex regulatory mechanisms. The most recent experimental study discovered that transgenic expression of PAPP-A in murine arterial smooth muscle accelerates atherosclerotic lesion development [34]. Thus, PAPP-A is suggested as a potential therapeutic target in the control of atherosclerosis.

Our results indicate that a higher PAPP-A is mainly a short-time mortality predictor (within the first 200 days). If the patient survives this critical period, he/she has a good chance for further survival. In between, PAPP-A levels might have changed. For clarification, a study focused on time-dependent PAPP-A changes in healthy subjects and/or patients would be appreciated. Nevertheless, this is only a hypothesis and is not supported by sufficient statistical power due to the small number of patients.

From other markers of interest, neither PlGF nor MMP-2 and -9 levels had any significance for predicting the prognosis of HD patients. Each of these markers was of importance in the general population - elevated PlGF was associated with adverse cardiac outcomes during long-term follow-up [35], MMP-2 was identified as an independent predictor of all-cause mortality post-acute coronary syndrome [36], and the baseline serum MMP-9 level predicted long-term prognosis after coronary revascularization in stable coronary artery disease [37]. Our results support the hypothesis that data from the general population may not be true in specific populations. Our study population contained 261 patients and the observation period was 5 years. If these markers were also of high significance in HD patients, we suppose that it might also have been demonstrated in our study, at least in unadjusted analysis.

Despite some limitations - a relatively small sample size and involvement of prevalent not incident dialysis patients - the study clearly points out the significance of PAPP-A levels. Additionally, the study was performed in six centers and several physicians took care of the patients; however, statistically, there was no difference among mortality at the centers. Concerning the cause of death, judgment was sometimes very difficult, although two independent physicians were engaged, and might represent a potential source of bias.

In conclusion, this study has identified PAPP-A as an independent predictor of overall mortality and mortality due to infection in HD patients. Our results suggest a superior relationship of PAPP-A to infection/inflammation than to cardiovascular risk in HD patients. 


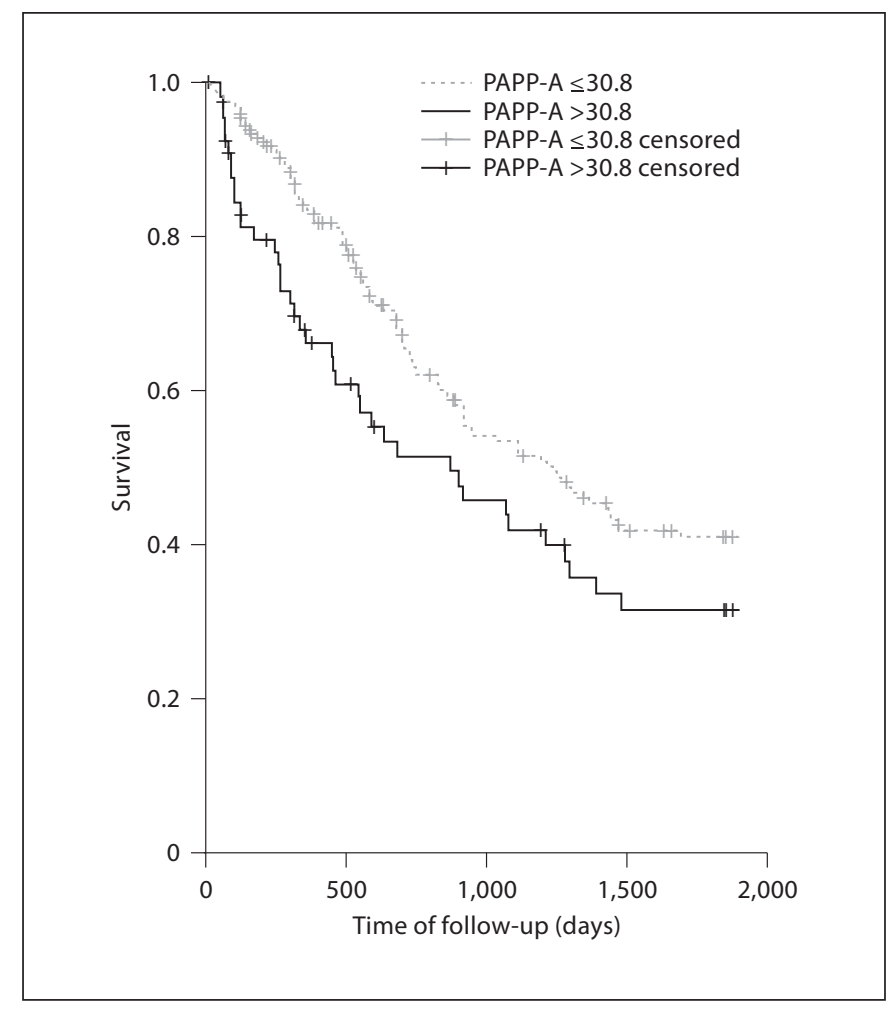

Fig. 2. Kaplan-Meier curves demonstrating overall mortality of HD patients with PAPP-A levels $<30.8$ and $>30.8 \mathrm{mIU} / \mathrm{l}$ (upper quartile). $\mathrm{p}=0.03$ (log-rank test).

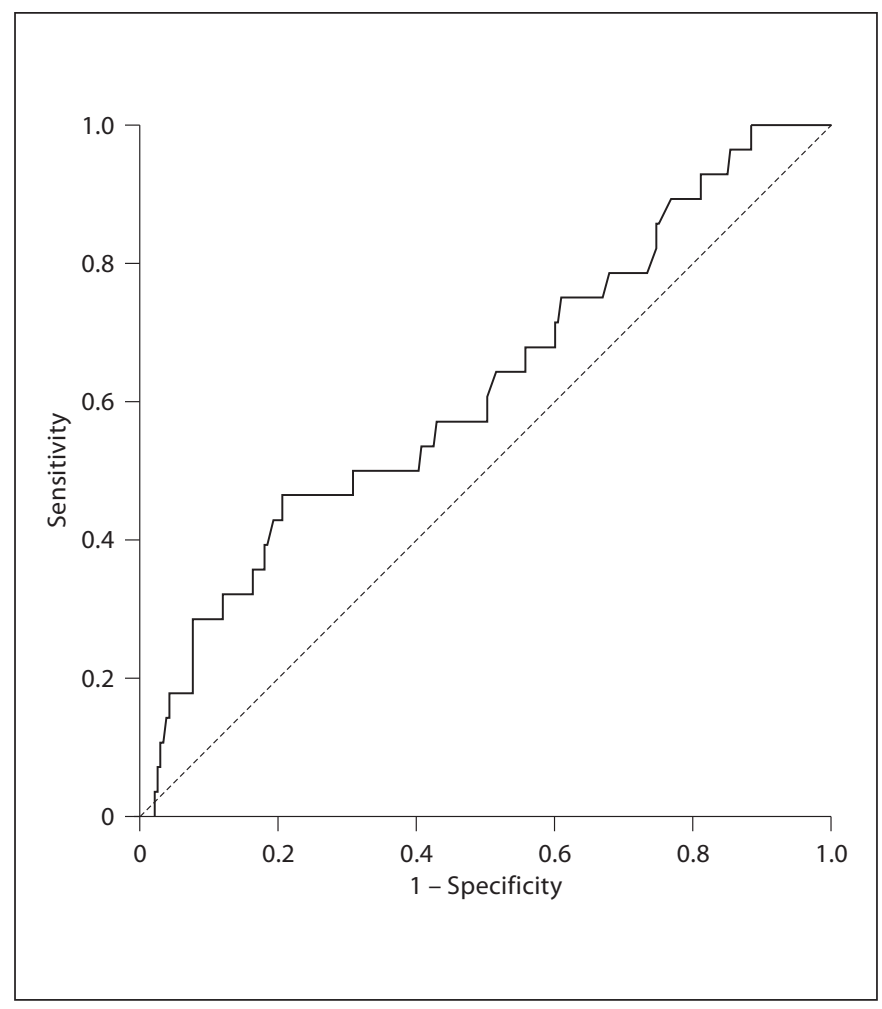

Fig. 3. ROC analysis: PAPP-A for 200 days' survival. $\mathrm{AUC}=0.62$, $\mathrm{p}=0.038$.

Table 3. Significant independent mortality predictors for overall, cardiovascular and infection-related mortality

\begin{tabular}{|c|c|c|c|c|c|c|}
\hline & \multicolumn{2}{|l|}{ Overall mortality } & \multicolumn{2}{|c|}{ Cardiovascular mortality } & \multicolumn{2}{|c|}{ Mortality due to infection } \\
\hline & HR (95\% CI) & $\mathrm{p}$ & $\operatorname{HR}(95 \% \mathrm{CI})$ & $\mathrm{p}$ & HR (95\% CI) & $\mathrm{p}$ \\
\hline PAPP-A & $1.237(1.060-1.444)$ & 0.007 & & & $1.416(1.115-1.798)$ & 0.004 \\
\hline cTnI & $1.411(1.200-1.658)$ & $<0.001$ & $1.470(1.208-1.790)$ & $<0.001$ & & \\
\hline Albumin & $0.722(0.595-0.876)$ & $<0.001$ & $0.588(0.447-0.774)$ & $<0.001$ & & \\
\hline Creatinine & $0.789(0.637-0.978)$ & 0.03 & & & $0.672(0.487-0.926)$ & 0.02 \\
\hline Retinol & $0.775(0.632-0.950)$ & 0.01 & $0.671(0.500-0.902)$ & 0.008 & & \\
\hline Parathormone & & & & & $0.621(0.364-1.058)$ & 0.08 , n.s. \\
\hline Age & $1.030(1.011-1.048)$ & 0.001 & & & & \\
\hline Diabetes mellitus & $1.625(1.128-2.340)$ & 0.009 & & & $2.966(1.474-5.966)$ & 0.002 \\
\hline CVD & $1.638(1.039-2.582)$ & 0.03 & $3.753(1.699-8.289)$ & 0.001 & & \\
\hline Transplantation & & & $0.121(0.016-0.893)$ & 0.04 & & \\
\hline
\end{tabular}

HRs and 95\% CIs for biochemical parameters are given per standard deviation and HRs for age are given per year. HRs were obtained using uni- or multivariate Cox analysis. Biochemical parameters and age were treated as continuous variables. Transplant was considered a time-dependent covariate in both univariate unadjusted and multivariate fully adjusted analysis. Fully adjusted analysis uses stratification for membrane type (low- or high-flux) and takes into consideration significant biochemical predictors in the first step and demographic and clinical data in the second step. CVD = Cardiovascular disease; $n . s .=$ not significant (exclusion criteria of backward method $\mathrm{p}>0.1$ ). 


\section{Acknowledgements}

The study was supported by grant IGA MH CZ NS/10043$4 / 2008$ and by research project MSM 0021620807. The authors are thankful to the physicians and nurses of the cooperating dialysis centers for technical assistance, especially to Dr. Markéta Kratochvilová and Dr. Magdaléna Hodková (Prague), Dr. Petr Gorun (Ústí nad Orlicí), Dr. Zdeněk Hobzek and Mrs. Anna Žd’ánská (Písek), Dr. Jiřina Suchanová and Dr. Eva Křížová (Tábor) and Dr. Zuzana Nýdlová (Strakonice). The authors are equally thankful to the laboratory staff for excellent laboratory skills, especially to Dr. Jiřina Soukupová, MSc., Jana Uhrová, Drahomíra Springer, $\mathrm{PhD}, \mathrm{MSc}$, Milada Koštířová and Mrs. Dita Hudcová, and to Dr. Oskar Zakiyanov for English proofreading.

\section{Disclosure Statement}

The authors have no conflicts of interest to declare.

\section{References}

1 Foley RN, Parfrey PS, Sarnak MJ: Clinical epidemiology of cardiovascular disease in chronic renal disease. Am J Kidney Dis 1998; 32:S112-S119.

-2 Bayes-Genis A, Conover CA, Overgaard MT, et al: Pregnancy-associated plasma protein A as marker of acute coronary syndromes. $\mathrm{N}$ Engl J Med 2001;345:1057-1059.

3 Wald NJ, Kennard A, Hackshaw AK: First trimester serum screening for Down's syndrome. Prenat Diagn 1995;15:1227-1240.

-4 Bonno M, Oxvig C, Kephart GM, et al: Localization of pregnancy-associated plasma protein-A and colocalization of pregnancyassociated protein-A messenger ribonucleic acid and eosinophil granule major basic protein messenger ribonucleic acid in placenta. Lab Invest 1994;71:560-566.

5 Overgaard MT, Oxvig C, Christiansen M, et al: Messenger ribonucleic acid levels of pregnancy-associated plasma protein-A and the proform of eosinophil major basic protein: expression in human reproductive and nonreproductive tissues. Biol Reprod 1999;61: 1083-1089.

-6 Lawrence JB, Oxvig C, Overgaard MT, et al: The insulin-like growth factor (IGF)-dependent IGF binding protein- 4 protease secreted by human fibroblasts in pregnancy-associated plasma protein-A. Proc Natl Acad Sci USA 1999;96:3149-3153.

7 Laursen LS, Overgaard MT, Søe R, et al: Pregnancy-associated plasma protein-A (PAPP-A) cleaves insulin-like growth factor binding protein (IGFBP)-5 independent of IGF: implications for the mechanism of IGFBP-4 proteolysis by PAPP-A. FEBS Lett 2001;504:36-40.

-8 Monget P, Mazerbourg S, Delpuech T, et al: Pregnancy-associated plasma protein-A is involved in insulin-like growth factor binding protein-2 (IGFBP-2) proteolytic degradation in bovine and porcine preovulatory follicles: identification of cleavage site and characterization of IGFBP-2 degradation. Biol Reprod 2003;68:77-86.
9 Jones JI, Prevette T, Gockerman A, Clemmons DR: Ligand occupancy of the $\alpha_{V} \beta_{3}$ integrin is necessary for smooth muscle cells to migrate in response to insulin-like growth factor. Proc Natl Acad Sci USA 1996;93: 2482-2487.

10 Renier G, Clement I, Desfaits AC, Lambert A: Direct stimulatory effect of insulin-like growth factor-I on monocyte and macrophage tumor necrosis factor- $\alpha$ production. Endocrinology 1996;137:4611-4618.

11 Conti E, Andreotti F, Zuppi C: Pregnancyassociated plasma protein a as predictor of outcome in patients with suspected acute coronary syndromes. Circulation 2004;109: e211-e212.

12 Lund J, Ruin QP, Ilva T, et al: Circulating pregnancy-associated plasma protein A predicts outcome in patients with acute coronary syndrome but not troponin I elevation. Circulation 2003;108:1924-1926.

13 Kalousová M, Sulková S, Fialová L, et al: Glycoxidation and inflammation in chronic hemodialysis patients. Nephrol Dial Transplant 2003;18:2577-2581.

14 Fialová L, Kalousová M, Soukupová J, et al: Relationship of pregnancy-associated plasma protein A to renal function and dialysis modalities. Kidney Blood Press Res 2004;27: $88-95$.

15 Kalousová M, Bartošová K, Zima T, Skibová J, Teplan V, Viklický O: Pregnancy-associated plasma protein A and soluble receptor for advanced glycation end products after kidney transplantation. Kidney Blood Press Res 2007;30:31-37.

16 Kalousová M, Hořejší M, Fialová L, et al: Increased levels of pregnancy-associated plasma protein A are associated with mortality of haemodialysis patients: preliminary results. Blood Purif 2004;22:298-300.

17 Etter C, Straub Y, Hersberger M, et al: Pregnancy-associated plasma protein $\mathrm{A}$ is an independent short-time predictor of mortality in patients on maintenance haemodialysis. Eur Heart J 2010;31:354-359.
18 Lauzurica R, Pastor C, Bayes B, Hernandez JM, Romero M: Pretransplant pregnancyassociated plasma protein-A as a predictor of chronic allograft nephropathy and posttransplant cardiovascular events. Transplantation 2005;80:1441-1446.

19 Apple FS, Wu AH, Mair J, et al: Committee on Standardization of Markers of Cardiac Damage of the IFCC. Future biomarkers for detection of ischemia and risk stratification in acute coronary syndrome. Clin Chem 2005;51:810-824.

20 Kalousová M, Kuběna AA, Koštířová M, et al: Lower retinol as an independent predictor of mortality in long-term hemodialysis patients: a prospective observational cohort study. Am J Kidney Dis 2010;6:513-521.

21 Heeschen C, Dimmeler S, Hamm CW, Fichtischerer S, Simoons ML, Zeiher AM, CAPTURE Study Investigators: Pregnancy-associated plasma protein A levels in patients with acute coronary syndromes: comparison with markers of systemic inflammation, platelet activation, and myocardial necrosis. J Am Coll Cardiol 2005;45:229-237.

22 Elesber AA, Conover CA, Denktas AE, et al: Prognostic value of circulating pregnancyassociated plasma protein levels in patients with chronic stable angina pectoris. Eur Heart J 2006;27:1678-1684.

23 Mueller T, Dieplinger B, Forstner T, Poelz W, Haltmayer M: Pregnancy-associated plasma protein A as a marker for long-term mortality in patients with peripheral atherosclerosis: inconclusive findings from the Linz Peripheral Arterial Disease (LIPAD) study. Clin Chem Lab Med 2010;48:537-542.

24 Astrup AS, Tarnow L, Christiansen M, Hansen PR, Parving HH, Rossing P: Pregnancyassociated plasma protein A in a large cohort of Type 1 diabetic patients with and without diabetic nephropathy - a prospective followup study. Diabet Med 2007;24:1381-1385.

25 Lauzuriza R, Pastor MC, Bayes B, et al: Pretransplant inflammation: a risk factor for delayed graft function? J Nephrol 2008;21:221228.
Kalousová/Benáková/Kuběna/ Dusilová-Sulková/Tesař/Zima 
-26 Resch ZT, Chen BK, Bale LK, Oxvig C, Overgaard MT, Conover CA: Pregnancy-associated plasma protein a gene expression as a target of inflammatory cytokines. Endocrinology 2004;145:1124-1129.

27 Conover CA, Harrington SC, Bale LK: Differential regulation of pregnancy-associated plasma protein A in human coronary artery endothelial cells and smooth muscle cells. Growth Horm IGF Res 2008;18:213220 .

$\checkmark 28$ Conover CA, Bale LK, Harrington SC, Resch ZT, Overgaard MT, Oxvig C: Cytokine stimulation of pregnancy-associated plasma protein A expression in human coronary artery smooth muscle cells: inhibition by resveratrol. Am J Physiol Cell Physiol 2006;290: C183-C188.

-29 Crea F, Andreotti F: Pregnancy-associated plasma protein-A and coronary atherosclerosis: marker, friend or foe? Eur Heart J 2005; 26:2075-2076.
30 Conti E, Carrozza C, Capoluongo E, et al: Insulin-like growth factor-1 as vascular protective factor. Circulation 2004;110:22602265.

-31 Watanabe S, Tamura T, Ono K, et al: Insulinlike growth factor axis (insulin-like growth factor-I/insulin-like growth factor-binding protein-3) as a prognostic predictor of heart failure: association with adiponectin. Eur J Heart Fail 2010;12:1214-1222.

-32 Andreassen M, Kistorp C, Raymond I, et al: Plasma insulin-like growth factor I as predictor of progression and all-cause mortality in chronic heart failure. Growth Horm IGF Res 2009;19:486-490.

$\checkmark 33$ Kumar A, Mohan S, Newton J, et al: Pregnancy-associated plasma protein A regulates myoblast proliferation and differentiation through an insulin-like growth factor-dependent mechanism. J Biol Chem 2005;280: 37782-37789.
34 Conover CA, Mason MA, Bale LK, et al: Transgenic overexpression of pregnancy-associated plasma protein A in murine arterial smooth muscle accelerates atherosclerotic lesion development. Am J Physiol Heart Circ Physiol 2010;299:H284-H291.

35 Lenderink T, Heeschen C, Fichtlscherer S, et al: CAPTURE Investigators: Elevated placental growth factor levels are associated with adverse outcomes at four-year followup in patients with acute coronary syndromes. J Am Coll Cardiol 2006;47:307-311.

36 Dhillon OS, Khan SQ, Narayan HK, et al: Matrix metalloproteinase-2 predicts mortality in patients with acute coronary syndrome. Clin Sci (Lond) 2009;118:249-257.

37 Ye YX, Leu HB, Wu TC, Lin SJ, Chen JW: Baseline serum matrix metalloproteinase-9 level predicts long-term prognosis after coronary revascularizations in stable coronary artery disease. Clin Biochem 2008;41:292298. 